\title{
Application of Dried Blood Spots and Serum Samples \\ for the Determination of Vitamin D Metabolites in the Group of Healthy Women and with Hashimoto's Thyroiditis
}

\author{
R. Rola ${ }^{1,2}$ (E. E. Trusewicz ${ }^{3} \cdot$ T. Bieńkowski $^{2} \cdot$ S. Studzińska ${ }^{1}$
}

Received: 14 March 2021 / Revised: 21 April 2021 / Accepted: 29 April 2021 / Published online: 11 May 2021

(c) The Author(s) 2021

\begin{abstract}
Purpose The relationship between Hashimoto's thyroiditis and vitamin D concentration was already presented in many studies. The aim of this study was to analyze the differences in the concentration of vitamin D metabolites between healthy women and women with Hashimoto's thyroiditis (HT).

Methods The quantitative analysis of five vitamin D metabolites was carried out using liquid chromatography coupled with tandem mass spectrometry. The analyzed materials were serum and dried blood spots (DBS). The results obtained for the two materials were also compared.

Results No statistically significant differences were found in the mean concentration of the $25(\mathrm{OH}) \mathrm{D}_{3}, 25(\mathrm{OH}) \mathrm{D}_{2}$, $24,25(\mathrm{OH})_{2} \mathrm{D}_{3}, 1,25(\mathrm{OH})_{2} \mathrm{D}_{3}$ metabolites between the test and the control groups. However, a strong correlation was found between the $25(\mathrm{OH}) \mathrm{D}_{3}$ and $24,25(\mathrm{OH})_{2} \mathrm{D}_{3}$ metabolites.

Conclusion The study showed that healthy women and women with Hashimoto's disease had similar concentration of vitamin D metabolites. Research also proved that DBS is a good alternative to serum. The differences in $25(\mathrm{OH}) \mathrm{D}$ concentration were not statistically significant (17.0 and $15.5 \mathrm{ng} \mathrm{mL}^{-1}$ for serum and DBS, respectively). DBS can be successfully used in research on a large group of people, since the process of material collection, as well as sample preparation, is fast and simple. It is also easy to transport and store, and requires small volume of blood.
\end{abstract}

Keywords Vitamin D $\cdot$ Calcitriol $\cdot$ Female $\cdot$ Liquid chromatography $\cdot$ Mass spectrometry $\cdot$ Hashimoto thyroiditis $\cdot$ Autoimmune thyroid disease

\section{Introduction}

Hashimoto's disease, also known as chronic lymphocytic thyroiditis is one of the chronic thyroid autoimmune diseases. It is the most common cause of hypothyroidism. It occurs much more commonly in women than men [1].

The results of many observational studies suggest that there is a relationship between low concentration of vitamin

R. Rola

r.rola@doktorant.umk.pl

1 Chair of Environmental Chemistry and Bioanalytics, Faculty of Chemistry, Nicolaus Copernicus University in Torun, 7 Gagarin St., 87-100 Toruń, Poland

2 Masdiag-Diagnostic Mass Spectrometry Laboratory, 33 Stefana Żeromskiego St., 01-882 Warsaw, Poland

3 Dieta i Fitness, Valmaar Enterprises, Warsaw, Poland
D and Hashimoto's disease [2]. The term "vitamin D" usually refers to its metabolized forms rather than the native compound. The most common is the concentration of calcidiol $(25(\mathrm{OH}) \mathrm{D})$, which is the sum of the calcifediol $(25(\mathrm{OH})$ $\mathrm{D}_{3}$ ) and ercalcidiol $\left(25(\mathrm{OH}) \mathrm{D}_{2}\right)$. Reduced serum 25(OH)D concentration was found in patients with Hashimoto's thyroiditis regardless of age, sex and body weight [3]. There is an association between severity of vitamin D deficiency and duration of Hashimoto's disease, thyroid volume and thyroid peroxidase antibodies (TPO) [4]. A meta-analysis of Wang et al. [5] showed that patients with thyroid autoimmune disease had lower concentration of $25(\mathrm{OH}) \mathrm{D}$ and were more likely to have vitamin D deficiency. In turn, Yasmeh et al. [6] proved that people with Hashimoto don't have a lower $25(\mathrm{OH}) \mathrm{D}$ concentration compared to healthy people.

There are several techniques used to determine the concentration of vitamin D metabolites, which differ primarily in accuracy. These include: radioimmunoassays (RIA), 
immunoenzymatic assays (ELISA), chemiluminescent assays (CLIA) and direct techniques: high performance liquid chromatography with UV detection (HPLC-UV) or tandem mass spectrometry (LC-MS/MS) [7]. Until now, chemiluminescence-based immunoassays have been used to analyze vitamin D metabolites in people with thyroid disorders. Due to various analytical problems, LC-MS/MS technique is gaining more popularity, although it is not as throughput, as automated immunoassays. It is currently a reference method. Compared to other techniques, it guarantees better accuracy and reproducibility [7]. Therefore, the following studies used the LC-MS/MS technique to present its great diagnostic potential.

The main aim of this study was to investigate the difference in concentration of five vitamin D metabolites between two groups of adult women - healthy and with Hashimoto's disease. Two biological materials were analyzed-serum and dried blood spots (DBS). Compared to previous studies, profiling of vitamin D metabolites involved not only $25(\mathrm{OH})$ $\mathrm{D}_{3}$ and $25(\mathrm{OH}) \mathrm{D}_{2}$, but also C-3 epimer of calcifediol (3-epi$\left.25(\mathrm{OH}) \mathrm{D}_{3}\right),(24 \mathrm{R})$-hydroxycalcifediol $\left(24,25(\mathrm{OH})_{2} \mathrm{D}_{3}\right)$ and calcitriol $\left(1,25(\mathrm{OH})_{2} \mathrm{D}_{3}\right)$. Moreover, the use of DBS in this type of research was done for the first time. Consequently, it allowed to reduce the volume of biological material significantly and facilitated the sample preparation.

\section{Materials and Methods}

\section{Qualification to the Study and Material Collection}

The study included women with Hashimoto's disease and a healthy control group. The inclusion criteria for both studied groups were as follows: no vitamin D supplementation, limited sun exposure, Body Mass Index (BMI) in the range of $18.5-30 \mathrm{~kg} \mathrm{~m}^{2}$, no pregnancy, age between $20-50$ years. What is more, the study group had to have medically documented Hashimoto's disease (presence of anti-TPO or antiTG antibodies and ultrasound image).

Biological material was collected from 98 women meeting the above criteria (56 with Hashimoto and 42 healthy participants). Participants signed the patient's consent and received a brochure with the project description. Two biological materials were collected, including serum and capillary blood in the form of DBS. All experiments were approved by the ethics committee at Medical University of Bialystok (consent of the bioethics commission no. R-I-002/143/2017).

\section{Materials}

Standards of vitamin D metabolites and their internal standards (ISTD), including $25(\mathrm{OH}) \mathrm{D}_{3}, 3-$ epi-25(OH)
$\mathrm{D}_{3}, 25(\mathrm{OH}) \mathrm{D}_{2}, 24,25(\mathrm{OH})_{2} \mathrm{D}_{3}, 1,25(\mathrm{OH})_{2} \mathrm{D}_{3}, \mathrm{~d}_{6}-25(\mathrm{OH})$ $\mathrm{D}_{3}, \mathrm{~d}_{3}-3-$ epi-25(OH) $\mathrm{D}_{3}, \mathrm{~d}_{3}-25(\mathrm{OH}) \mathrm{D}_{2}, \mathrm{~d}_{6}-24,25(\mathrm{OH})_{2} \mathrm{D}_{3}$, $\mathrm{d}_{3}-1,25(\mathrm{OH})_{2} \mathrm{D}_{3}$ were purchased from IsoSciences (Ambler, PA, USA). Dried blood spots were collected using Munktell TFN-Specimen Collection Cards $(76 \times 108 \mathrm{~mm})$ (Bärenstein, Germany). Serum calibration standards were prepared with the use of vitamin D-free serum that was ordered from Golden West Biologicals (Temecula, CA, USA). DBS calibration cards were prepared using blood substitute prepared from human red blood cells and vitamin D-free serum. Red blood cells were obtained from whole blood collected into test tube containing sodium citrate as an anticoagulant. They were flushed with physiological saline before mixing them with the vitamin D-free serum.

Various reagents were used during sample preparation. Solvents, such as methanol, ethyl acetate, acetonitrile, water (Witko Sp. z o.o., Łódź, Poland) were used. Sample preparation included derivatization with 4-(4'-dimethylaminophenyl)-1,2,4-triazoline-3,5-dione (DAPTAD) that was synthesized by Masdiag Laboratory (Warsaw, Poland).

Two chromatographic columns were used: COSMOSIL $\mathrm{PBr}(2.6 \mu \mathrm{m} ; 100 \times 2.1 \mathrm{~mm}$; Nacalai Tesque, Kyoto, Japan) and Eclipse XDB-C18 (1.7 $\mu \mathrm{m} ; 50 \times 4.6 \mathrm{~mm}$; Agilent Technologies, Santa Clara, CA, USA). Mobile phases were prepared with the use of acetonitrile (ACN), water, methanol (MeOH) (Witko Sp. z o.o., Łódź, Poland) and formic acid (FA) (Merck KGaA, Darmstadt, Germany). All solvents were of LC-MS grade.

\section{Apparatus and Chromatographic Conditions}

Vitamin D metabolites were determined using ExionLC ${ }^{\mathrm{TM}}$ analytical HPLC system coupled with QTRAP® 4500 MS/ MS system (Sciex, Framingham, MA, USA). LC-MS analyses were performed using electrospray ionization (ESI) in a positive mode. Ion source operating parameters were as follows: curtain gas (CUR) 30, collision gas (CAD) 7, ion spray voltage (IS) $3500 \mathrm{~V}$, temperature of drying gas (TEM) $500^{\circ} \mathrm{C}$, nebulizing gas (GS1) 40, drying gas (GS2) 50. CUR, CAD, GS1 and GS2 are expressed in arbitrary units. Multiple reaction monitoring (MRM) was used for the quantitative analyses. The raw data were collected with the use of Analyst 1.6.3. Multiquant 1.7 was used to process and quantify collected data.

The chromatographic analysis of $25(\mathrm{OH}) \mathrm{D}_{3}, 3$-epi$25(\mathrm{OH}) \mathrm{D}_{3}, 25(\mathrm{OH}) \mathrm{D}_{2}, 24,25(\mathrm{OH})_{2} \mathrm{D}_{3}$ metabolites was performed using Eclipse XDB-C18 $1.7 \mu \mathrm{m}(50 \times 4.6 \mathrm{~mm})$ at the flow rate of $0.8 \mathrm{~mL} \mathrm{~min}{ }^{-1}$. The temperature of the column oven was $40^{\circ} \mathrm{C}$. The mobile phase consisted of water (A) and acetonitrile (B), both containing $0.1 \%$ formic acid. The 
gradient elution program was as follows: $0 \mathrm{~min}$. $-50 \% \mathrm{~B}$, 2.5 min. $-78 \%$ B, 3.2 min. $-98 \%$ B, 4.5 min. $-98 \%$ B, $4.6 \mathrm{~min}$. $-50 \%$ B. Total run time was $5.5 \mathrm{~min}$.

The chromatographic analysis of $1,25(\mathrm{OH})_{2} \mathrm{D}_{3}$ metabolite was performed using COSMOSIL $\mathrm{PBr}(2.6 \mu \mathrm{m}$; $100 \times 2.1 \mathrm{~mm}$ ) at the flow rate of $0.6 \mathrm{~mL} \mathrm{~min}^{-1}$. The temperature of the column oven was $45^{\circ} \mathrm{C}$. The mobile phase consisted of water (A) and methanol (B), both with addition of $0.1 \%$ formic acid. The gradient elution program was as follows: $0 \mathrm{~min}$. $-65 \% \mathrm{~B}, 0.5 \mathrm{~min}$. $-80 \% \mathrm{~B}, 8.0 \mathrm{~min}$. $-88 \%$ B, 8.2 min. $-99 \%$ B, 9.3 min. $-99 \%$ B, 9.5 min. $-65 \%$ B. Total run time was $10.5 \mathrm{~min}$.

\section{Sample Preparation}

Sample preparation included two different biological materials (DBS and serum). Serum samples were prepared in two ways (separate procedure for calcitriol determination, separate for the rest of the vitamin D metabolites).

Determination of $25(\mathrm{OH}) \mathrm{D}_{3}, 3-$ epi- $25(\mathrm{OH}) \mathrm{D}_{3}, 25(\mathrm{OH})$ $\mathrm{D}_{2}, 24,25(\mathrm{OH})_{2} \mathrm{D}_{3}$ metabolites in serum and DBS was performed in the same manner as described previously $[8$, 9]. Serum sample preparation for calcitriol determination involved liquid-liquid extraction preceded by protein precipitation, in a similar manner to Ding et al. [10].

\section{Results and Discussion}

\section{LC-MS/MS Analysis of Vitamin D Metabolites-Serum and DBS}

The important stage of this study was assessment of the vitamin D metabolites concentration in healthy and sick women, who did not expose to sunlight and did not supplement with vitamin $\mathrm{D}_{3}$. The obtained results were used to compare these two materials, and in particular to show the possibilities of DBS as an alternative biological material.

There were two separate chromatographic methods, one for $1,25(\mathrm{OH})_{2} \mathrm{D}_{3}$ and one for the rest of the vitamin $\mathrm{D}$ metabolites. Due to the low concentration range of calcitriol, $400 \mu \mathrm{L}$ of serum was used in the sample preparation process, which was then purified and concentrated. The complex metabolism of vitamin D results in an approximately large number of structurally diversified metabolites. Additionally, isobaric interferences are present. Therefore, a relatively large number of false positive signals for calcitriol were observed as shown in Fig. 1a. The blue line corresponds to calcitriol and red line corresponds to its internal standard $\left(d_{3}-1,25(\mathrm{OH})_{2} \mathrm{D}_{3}\right)$. Among the two isomers of the $1,25(\mathrm{OH})_{2} \mathrm{D}_{3}$ metabolite, only one of them is not affected by interferences. A gradient elution was performed, but the increase in the organic phase was not rapid ( $8 \%$ of mobile phase B in 7.5 min.). Thanks to this, it was possible to find a narrow retention time window in which this compound was eluted. This single compound was separated using $\mathrm{PBr}$ column, where the fluorine atoms in the stationary phase are replaced with bromine ones. This solution gave a different selectivity, which was particularly useful in the analysis of this metabolite (stationary phases, such as octadecyl and phenyl did not have sufficient resolving power). Moreover, the organic modifier in the mobile phase was methanol, instead of acetonitrile. As a result, the full separation capabilities of the stationary phase were used (acetonitrile would weaken the pi-pi interactions). In contrast, the use of octadecyl stationary phase enabled the full separation of the other four vitamin D metabolites, including epimeric form, as well as additional interfering compounds (e.g. $25,26(\mathrm{OH})_{2} \mathrm{D}_{3}$ ). Hence, the obtained results were not overestimated, which is especially important in the clinical practice. Representative chromatograms are shown in Fig. 1. An additional reason to perform the above analyzes separately was due to different sample preparation protocols (calcitriol analysis required $400 \mu \mathrm{L}$ of material, while the rest of the vitamin D metabolites required $50 \mu \mathrm{L}$ ).

As written above, two biological materials were collected-serum and DBS. In the case of DBS, 4 metabolites were determined, i.e. $25(\mathrm{OH}) \mathrm{D}_{3}, 25(\mathrm{OH}) \mathrm{D}_{2}, 24,25(\mathrm{OH})_{2} \mathrm{D}_{3}$ and 3-epi-25(OH) $\mathrm{D}_{3}$. The serum analysis also included the less abundant $1,25(\mathrm{OH})_{2} \mathrm{D}_{3}$ metabolite. Then, the obtained results were compared with each other. The most important conclusion is that both materials are positively correlated with each other. The average difference between serum and DBS was $0.7,7.3,5.3$ and $11 \%$ for $24,25(\mathrm{OH})_{2} \mathrm{D}_{3}, 25(\mathrm{OH})$ $\mathrm{D}_{3}, 25(\mathrm{OH}) \mathrm{D}_{2}$ and 3-epi-25(OH) $\mathrm{D}_{3}$, respectively. Figure 2 presents a graph comparing the results obtained for the serum and DBS samples for the $25(\mathrm{OH}) \mathrm{D}$ metabolite. Moreover, the Bland-Altman plot is shown in Fig. 3 to evaluate the agreement among these two different measurement techniques and to identify any systematic difference. All of the data points lie within $\pm 1.96 \bullet \mathrm{s}$ of the mean difference. This leads to the conclusion that both materials may be used interchangeably. Each of these two biological materials has its own advantages depending on the intended use. Serum analysis is characterized by greater accuracy and repeatability. Moreover, it allows for the determination of calcitriol, which is present in the serum at a concentration of $\mathrm{pg} \mathrm{mL}^{-1}$. However, collecting this material requires a visit to the blood collection point. Additionally, the storage and transportation are costly due to the low temperatures required. On the other hand, the use of DBS requires a small volume of biological material and is easy to store and transport. The biggest advantage is the possibility of blood self-collection. The serum sample preparation involves protein precipitation and extraction with acetonitrile. In turn, DBS sample preparation is based only on the direct extraction of the determined 
Fig. 1 Representative chromatograms for the analysis of vitamin D metabolites. Conditions: (1) COSMOSIL PBr

$(2.6 \mu \mathrm{m} ; 100 \times 2.1 \mathrm{~mm})$; mobile phase: water (a) and methanol (b) with $0.1 \% \mathrm{FA}$; flow rate: $0.6 \mathrm{~mL} \mathrm{~min}^{-1}$; gradient elution program: $0 \mathrm{~min} .-65 \% \mathrm{v} / \mathrm{v} \mathrm{B}$, $0.5 \mathrm{~min} .-80 \% \mathrm{v} / \mathrm{v} \mathrm{B}, 8.0 \mathrm{~min}$ $-88 \%$ v/v B, 8.2 min. $-99 \%$ v/v B, 9.3 min. $-99 \%$ v/v B, $9.5 \mathrm{~min} .-65 \%$ v/v B; column oven temperature: $45^{\circ} \mathrm{C}$; (2) ZORBAX XDB-C18 (1.7 $\mu \mathrm{m}$; $50 \times 4.6 \mathrm{~mm})$; mobile phase: water (A) and acetonitrile (B) with $0.1 \% \mathrm{FA}$; flow rate: $0.8 \mathrm{~mL} \mathrm{~min}^{-1}$; gradient elution program: $0 \mathrm{~min} .-50 \% \mathrm{v} / \mathrm{v} \mathrm{B}$, $2.5 \mathrm{~min} .-78 \%$ v/v B, $3.2 \mathrm{~min}$. $-98 \%$ v/v B, 4.5 min. $-98 \%$ v/v B, 4.6 min. $-50 \%$ v/v B, $5.5 \mathrm{~min} .-50 \%$ v/v B; column oven temperature: $40{ }^{\circ} \mathrm{C}$.

Notation: A-the analysis of calcitriol in real serum sample using $\mathrm{PBr}$ column, $\mathrm{B}$ - the analysis of standard mixture of vitamin D metabolites using XDB-C18 column; blue chromatogram-Extracted Ion Chromatogram of calcitriol, red chromatogram-Extracted Ion Chromatogram of calcitriol ISTD; $1-1,25(\mathrm{OH})_{2} \mathrm{D}_{3}$, $2-d_{3}-1,25(\mathrm{OH})_{2} \mathrm{D}_{3}$, $3-24,25(\mathrm{OH})_{2} \mathrm{D}_{3}, 4-3-e p i-$ $25(\mathrm{OH}) \mathrm{D}_{3}, 5-25(\mathrm{OH}) \mathrm{D}_{3}$, $6-25(\mathrm{OH}) \mathrm{D}_{2}$
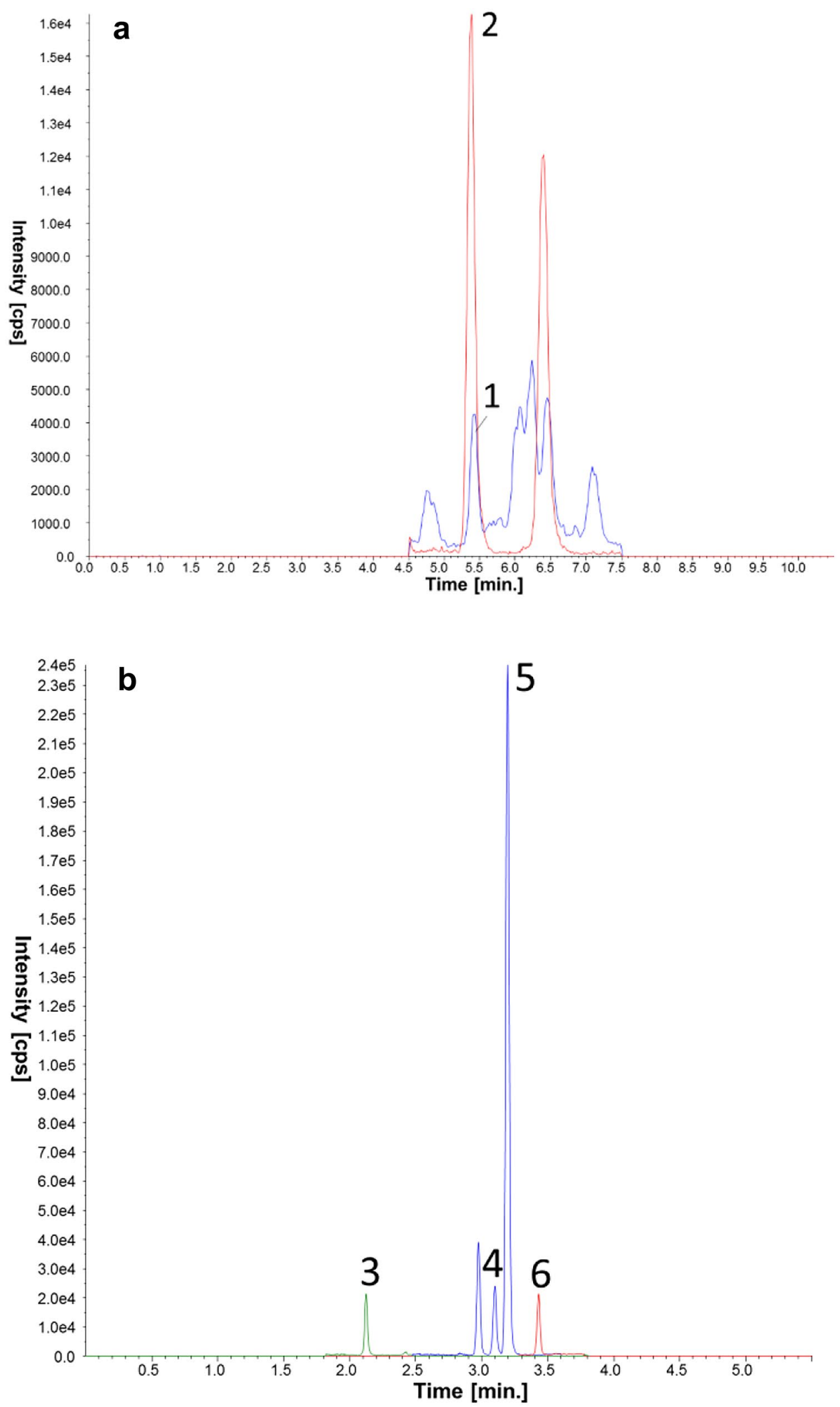

compounds from the filter paper with methanol. Both procedures have an additional step of the derivatization to increase the sensitivity by facilitating the ionization process. Overall, both sample preparation methods are fast, efficient, easy to automate, and they enable extracting all vitamin $\mathrm{D}$ metabolites with high recovery values (90-110\%). 


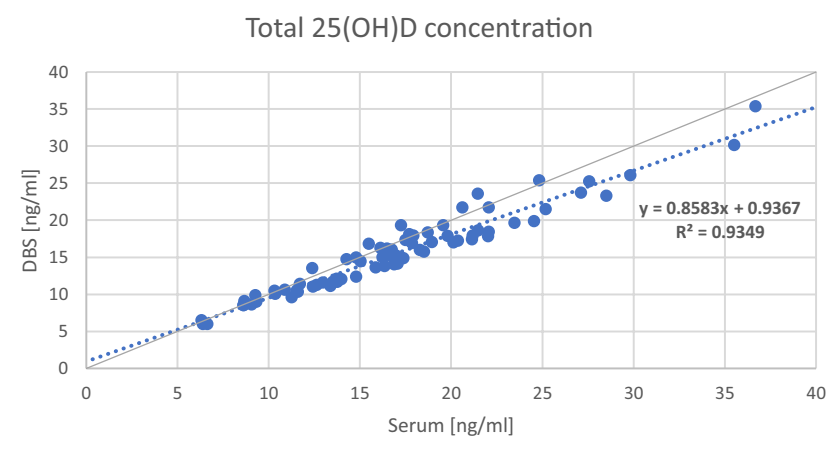

Fig. 2 Graph showing the correlation of the results obtained from the analysis of serum and DBS in terms of total $25(\mathrm{OH}) \mathrm{D}$ concentration

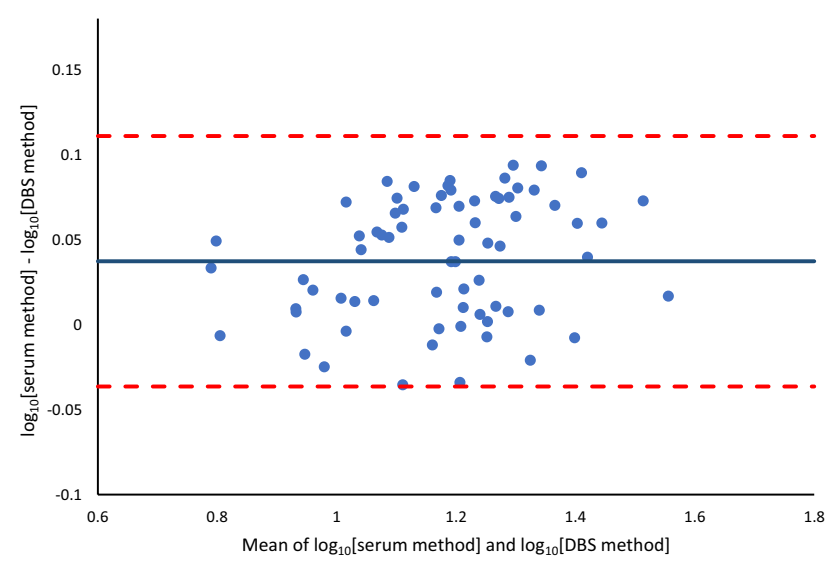

Fig. 3 Bland-Altman plot of log-transformed data

As described in the work [8], the total measurement error in the case of DBS is mostly affected by the quality of the collected material and hematocrit. Using this type of material in different research projects could allow for gathering a larger study group. People willing to participate in the study would not have to come to the blood collection point. Instead, the material would be sent directly to the laboratory after self-collection. It is worth mentioning that such use of DBS in profiling of vitamin D metabolites in the group of people with Hashimoto's disease was made for the first time.

\section{Vitamin D Status of Healthy Women and with Hashimoto's Thyroiditis}

In the following discussion, the results will be referred to the guidelines for the European population. The range of $30-50 \mathrm{ng} \mathrm{mL}^{-1}$ is considered to be normal $25(\mathrm{OH}) \mathrm{D}$ concentration [11]. Optimal calcitriol concentration is considered to be $20-60 \mathrm{pg} \mathrm{mL}^{-1}$ [11]. Values of the $25(\mathrm{OH}) \mathrm{D}_{3}$ to $24,25(\mathrm{OH})_{2} \mathrm{D}_{3}$ ratio were compared to reference values developed by the laboratory performing quantitative analysis. These values were determined based on population studies. A ratio value below 6.1 means excessive catabolism of $25(\mathrm{OH}) \mathrm{D}_{3}$, in the range of 6.1-16.7 means balanced catabolism of $25(\mathrm{OH}) \mathrm{D}_{3}$, and above 16.7 means inhibited catabolism.

Serum concentration of vitamin D metabolites is presented in Table 1 (for the test group and for the control group). The average concentration of $25(\mathrm{OH}) \mathrm{D}$ was $18.3 \mathrm{ng} \mathrm{mL}^{-1}$ in women with Hashimoto and $16.5 \mathrm{ng} \mathrm{mL}^{-1}$ in healthy women. These differences are not statistically significant. Based on the $25(\mathrm{OH}) \mathrm{D}_{3}$ to $24,25(\mathrm{OH})_{2} \mathrm{D}_{3}$ ratio, none of the women in both groups had excessive elimination of $25(\mathrm{OH}) \mathrm{D}_{3}$. This is consistent with the fact that the value of the above ratio decreases as the concentration of $25(\mathrm{OH}) \mathrm{D}_{3}$ increases. It was also found that $7.32 \%$ of women with Hashimoto and $26.67 \%$ of women in the control group had inhibited $25(\mathrm{OH}) \mathrm{D}_{3}$ elimination. It is related with the low concentration of $25(\mathrm{OH}) \mathrm{D}_{3}$ and, consequently, the low concentration of $24,25(\mathrm{OH})_{2} \mathrm{D}_{3}$. It is worth noting that the high $25(\mathrm{OH}) \mathrm{D}_{3}$ to $24,25(\mathrm{OH})_{2} \mathrm{D}_{3}$ ratio value was only due to the very low concentration of $25(\mathrm{OH}) \mathrm{D}_{3}$, and not for example idiopathic infantile hypercalcemia (IIH) [12].

The relationship between individual metabolites was investigated. An increase in the concentration of the $25(\mathrm{OH})$ $\mathrm{D}_{3}$ metabolite results in a proportional increase in the $24,25(\mathrm{OH})_{2} \mathrm{D}_{3}$ metabolite. The dependence curve does not pass through point 0 as shown in Fig. S1 (Supplementary materials). This indicates that below a certain concentration of the $25(\mathrm{OH}) \mathrm{D}_{3}$ metabolite, 24-hydroxylase activity is inhibited, or at least limited. These observations are consistent with previous work [13]. A similar relationship was determined for the $1,25(\mathrm{OH})_{2} \mathrm{D}_{3}$ metabolite. There is no statistically significant correlation between $25(\mathrm{OH}) \mathrm{D}_{3}$ and $1,25(\mathrm{OH})_{2} \mathrm{D}_{3}$ metabolites in both groups. The serum concentration of $1,25(\mathrm{OH})_{2} \mathrm{D}_{3}$ depends mainly on renal function, parathyroid hormone (PTH) concentration and calcium and phosphorus supply [14]. High PTH, low calcium and phosphorus are the main stimulants of calcitriol production. To assess the vitamin D status, calcitriol should not be tested, as this may lead to misinterpretation. This metabolite has a short half-life and is strictly regulated. Its concentration is often normal or even elevated in patients with vitamin D deficiency due to elevated PTH levels. For these reasons, as well as on the basis of the obtained results, it can be concluded that the best indicator of vitamin D deficiency is not calcitriol, but the concentration of 25(OH)D. Different studies suggest that $24,25(\mathrm{OH})_{2} \mathrm{D}_{3}$ production is dependent on calcitriol. A higher concentration of $1,25(\mathrm{OH})_{2} \mathrm{D}_{3}$ induces an increase in the activity of the 24-hydroxylase enzyme and the formation of an inactive metabolite which is $24,25(\mathrm{OH})_{2} \mathrm{D}_{3}$. This mechanism is an important element in counteracting vitamin $\mathrm{D}$ intoxication, because excess of $25(\mathrm{OH}) \mathrm{D}_{3}$ is converted to $24,25(\mathrm{OH})_{2} \mathrm{D}_{3}[15]$. 


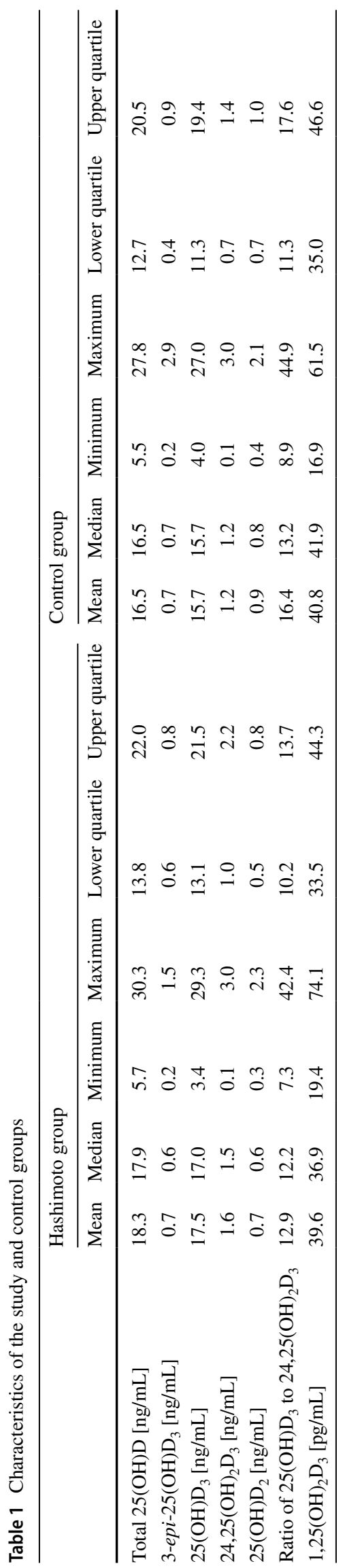

\section{Conclusion}

Analysis of the results revealed no statistically significant differences between serum 25(OH)D concentration in women with Hashimoto's disease and women in the control group. A strong correlation between $25(\mathrm{OH}) \mathrm{D}_{3}$ and $24,25(\mathrm{OH})_{2} \mathrm{D}_{3}$ metabolites was found. Nevertheless, there was no relationship between the $25(\mathrm{OH}) \mathrm{D}_{3}$ and $1,25(\mathrm{OH})_{2} \mathrm{D}_{3}$ metabolites.

Comparative studies between serum and DBS have shown that the material in the form of DBS is a good alternative to serum. Using DBS in this type of research will significantly facilitate the collection of material, as well as acquiring a larger group of people for testing. This type of biological material requires very low volume of blood $(<100 \mu \mathrm{L})$, reduces the risk of pathogen infection to a minimum, and primarily requires less invasive sampling. All of these features simplify the sample preparation process, including its collection.

The studies have provided an overview of the metabolic process and the use of the relationship between concentrations of individual metabolites to assess the body's supply of vitamin D. The results also proved the high research potential of the LC-MS/MS technique, which allowed for obtaining more accurate quantitative results in relation to the techniques and methods used so far.

Supplementary Information The online version contains supplementary material available at https://doi.org/10.1007/s10337-021-04047-6.

\section{Declarations}

Conflict of Interest The authors declare that they have no known competing financial interests or personal relationships that could have appeared to influence the work reported in this paper.

Ethical Approval All experiments were approved by the ethics committee at Medical University of Bialystok (consent of the bioethics commission no. R-I-002/143/2017).

Open Access This article is licensed under a Creative Commons Attribution 4.0 International License, which permits use, sharing, adaptation, distribution and reproduction in any medium or format, as long as you give appropriate credit to the original author(s) and the source, provide a link to the Creative Commons licence, and indicate if changes were made. The images or other third party material in this article are included in the article's Creative Commons licence, unless indicated otherwise in a credit line to the material. If material is not included in the article's Creative Commons licence and your intended use is not permitted by statutory regulation or exceeds the permitted use, you will need to obtain permission directly from the copyright holder. To view a copy of this licence, visit http://creativecommons.org/licenses/by/4.0/. 


\section{References}

1. Tunbridge WM, Evered DC, Hall R, Appleton D, Brewis M, Clark F, Evans JG, Young E, Bird T, Smith PA (1977) The spectrum of thyroid disease in a community: the Whickham survey. Clin Endocrinol 7(6):481-493

2. Štefanić M, Tokić S (2020) Serum 25-hydoxyvitamin D concentrations in relation to Hashimoto's thyroiditis: a systematic review, meta-analysis and meta-regression of observational studies. Eur J Nutr 59:859-872

3. Krysiak R, Szkróbka W, Okopień B (2017) The effect of vitamin $\mathrm{D}$ on thyroid autoimmunity in levothyroxine-treated women with hashimoto's thyroiditis and normal vitamin D status. Exp Clin Endocrinol Diabetes 125(4):229-233

4. Bozkurt NC, Karbek B, Ucan B, Sahin M, Cakal E, Ozbek M, Delibasi T (2013) The association between severity of vitamin D deficiency and Hashimoto's thyroiditis. Endocr Pract 19:479-484

5. Wang J, Lv S, Chen G, Gao C, He J, Zhong H, Xu Y (2015) Metaanalysis of the association between vitamin $\mathrm{D}$ and autoimmune thyroid disease. Nutrients 7(4):2485-2498

6. Yasmeh J, Farpour F, Rizzo V, Kheradnam S, Sachmechi I (2016) Hashimoto thyroiditis not associated with vitamin D deficiency. Endocr Pract 22(7):809-813

7. Farrell CL, Martin S, McWhinney B, Straub I, Williams P, Herrmann M (2012) State-of-the-art vitamin D assays: a comparison of automated immunoassays with liquid chromatography-tandem mass spectrometry methods. Clin Chem 58(3):531-542

8. Rola R, Kowalski K, Bienkowski T, Kolodynska-Goworek A, Studzinska S (2019) Development of a method for multiple vitamin D metabolite measurements by liquid chromatography coupled with tandem mass spectrometry in dried blood spots. Analyst 144:299-309

9. Rola R, Kowalski K, Bieńkowski T, Studzińska S (2020) Improved sample preparation method for fast LC-MS/MS analysis of vitamin D metabolites in serum. J Pharm Biomed Anal 190:113529

10. Ding S, Schoenmakers I, Jones K, Koulman A, Prentice A, Volmer DA (2010) Quantitative determination of vitamin D metabolites in plasma using UHPLC-MS/MS. Anal Bioanal Chem 398(2):779-789

11. Rusińska A, Płudowski P, Walczak M, Borszewska-Kornacka MK, Bossowski A, Chlebna-Sokół D, Czech-Kowalska J, Dob A, Franek E, Helwich E, Jackowska T, Kalina M, Konstantynowicz J, Książyk J, Lewiński A, Łukaszkiewicz J, MarcinowskaSuchowierska E, Mazur A, Michałus I, Peregud-Pogorzelski J, Romanowska H, Ruchała M, Socha P, Szalecki M, Wielgoś M, Zwolińska D, Zygmunt A (2018) Vitamin D supplementation guidelines for general population and groups at risk of vitamin $\mathrm{D}$ deficiency in poland-recommendations of the polish society of pediatric endocrinology and diabetes andthe expert panel with participation of national specialist consultants and representatives of scientific societies-2018 update. Front Endocrinol 9:246

12. Kaufmann M, Morse N, Molloy B, Cooper D, Schlingmann K, Molin A, Kottler M, Gallagher J, Armas L, Jones G (2017) Improved screening test for idiopathic infantile hypercalcemia confirms residual levels of serum 24,25-(OH)2D3 in affected patients. J Bone Miner Res 32(7):1589-1596

13. Wagner D, Hanwell HE, Schnabl K, Yazdanpanah M, Kimball S, Fu L, Sidhom G, Rousseau D, Cole DEC, Vieth R (2011) The ratio of serum 24,25-dihydroxyvitamin D3 to 25-hydroxyvitamin D3 is predictive of 25-hydroxyvitamin D3 response to vitamin D3 supplementation. J Steroid Biochem Mol Biol 126:72-77

14. Kennel KA, Drake MT, Hurley DL (2010) Vitamin D deficiency in adults: when to test and how to treat. Mayo Clin Proc 85(8):752-758

15. Dirks NF, Ackermans MT, Lips P, de Jongh RT, Vervloet M (2018) The when, what $\&$ how of measuring vitamin D in clinical medicine. Nutrients 10:482

Publisher's Note Springer Nature remains neutral with regard to jurisdictional claims in published maps and institutional affiliations. 